\title{
Enctis

\section{QUESTÕES ÉTNICO-RACIAIS NA BASE DIMENSIONS: DADOS DE PRODUÇÃO, USO E ATENÇÃO ON-LINE}

Ethnic-racial Issues in Dimensions: data on production, use and online attention

\author{
Sarah Rúbia de Oliveira Santos \\ Doutoranda e Mestre no Programa de Pós-Graduação em Gestão e Organização do Conhecimento da Universidade \\ Federal de Minas Gerais (PPG-GOC/UFMG). \\ Bacharela em Biblioteconomia pela Universidade Federal de Alagoas (UFAL) \\ Universidade Federal de Minas Gerais, Escola de Ciência da Informação (ECI), Belo Horizonte, Brasil \\ sarahrubia@ufmg.br \\ https://orcid.org/0000-0003-1118-3482 \\ Ronaldo Ferreira de Araújo \\ Doutor em Ciência da Informação \\ Universidade Federal de Alagoas, \\ Programa de Pós-Graduação em Ciência da Informação, \\ Maceió, Brasil \\ ronaldfa@gmail.com \\ https://orcid.org/0000-0003-0778-9561
}

\section{RESUMO}

A lista completa com informações dos autores está no final do artigo

Objetivo: Estudos de informação com ênfase nas temáticas étnico-raciais em pesquisas na Ciência da Informação ainda são incipientes, sobretudo no campo dos estudos métricos. O artigo busca investigar a produção e uso do conhecimento científico no campo de pesquisa dos estudos raciais por meio de indicadores bibliométricos e altmétricos.

Método: A pesquisa de abordagem exploratória e caráter quantitativo e descritivo analisa 4 mil registros e seus dados de citação recuperados na base de dados Dimensions a partir de buscas pelos descritores 'afro-brasileiros' e 'afroamericanos'. A orientação temática pela co-ocorrência de termos foi realizada nos VOSviewer e os dados altmétricos processados via API do Altmetric por meio da linguagem de programação Python.

Resultado: As pesquisas foram publicadas entre 1970 e 2020. A discussão afro-brasileira está centrada em temáticas relacionadas das humanidades e representação da mulher negra na literatura enquanto a afro-americana, gira em torno da saúde da população negra e as disparidades raciais com outros grupos étnicos. A atenção-online dos artigos foi mensurada por dados altmétricos e citações, observou-se grande contraste entre as publicações sobre as duas populações.

Conclusões: Os dados indicam que as temáticas étnico-raciais atraem o interesse dentro e fora da academia, e têm potencial para serem abordadas sob múltiplos enfoques, nas mais diversas áreas do conhecimento. Os pesquisadores e profissionais negros da Biblioteconomia e da Ciência da Informação possuem um vasto campo para realização de pesquisas e construção do conhecimento científico decolonilizado e antirracista.

PALAVRAS-CHAVE: Relações étnico-raciais. Bibliometria. Altmetria.

\section{ABSTRACT}

Objective: Information studies with an emphasis on ethnic-racial themes in Information Science research are still incipient, especially in the field of bibliometric studies. The article aims to investigate the production and use of scientific knowledge in the research field of racial studies through bibliometric and altmetric indicators.

Methods: The research has an exploratory approach, with quantitative and descriptive analyzes of 4,000 records and their citation data, which retrieved from the Dimensions database based on searches for the descriptors 'Afro-Brazilians' and 'Afro-Americans'. Thematic orientation for the co-occurrence of terms was carried out in VOSviewer and the altmetric data processed via the Altmetric API using the Python programming language.

Results: The publications cover the period between 1970 and 2020. On Afro-Brazilians, were identified discussions about topics related to teaching, education, quotas in universities and representation of black women in literature. As for AfricanAmericans, the themes revolve around the health of the black population and racial disparities with other ethnic groups. The online attention of the articles was measured by altmetric data and citations, there was a great contrast between publications about the two populations.

Conclusions: The data indicate that ethnic-racial themes attract interest inside and outside the academy, and have the potential to be addressed from multiple perspectives, in the most diverse academic fields. Black Librarianship 
professionals and Information Science researchers have a vast field to carry out research and build decolonized and antiracist scientific knowledge.

KEYWORDS: Ethnic-racial relations. Bibliometrics. Altmetrics

\section{INTRODUÇÃO}

O debate sobre as relações étnico-raciais, a população negra e seus direitos tem crescido nos últimos tempos, ganhando visibilidade no âmbito dos movimentos sociais, nos meios de comunicação, nas mídias sociais e, também, no meio acadêmico. Nesse movimento percebe-se, cada vez mais, a produção e compartilhamento de conhecimentos que destoam do estabelecido como o "único ponto de vista", e com isso a amplificação de vozes negras. A disseminação de conhecimento científico decolonizado, nesse sentido, possibilita a mudança de perspectivas já estabelecidas, mas que não representam o todo.

As fontes de informação sobre a temática étnico-racial desempenham papel essencial na disseminação desse conhecimento e funcionam "como instrumentos para minimizar as práticas de discriminação, inferiorização e invisibilidade da população negra na sociedade" (SANTOS; AQUINO, 2016, p. 50), no entanto, a produção científica sobre a temática étnico-racial ainda se encontra pouco evidente (MÜLLER, 2015).

Pensar as relações raciais no contexto acadêmico exige mais do que ser contra uma ciência racista, trata-se de construir "um diálogo permanente no combate ao racismo, seja dos conteúdos formativos, frentes de pesquisa e práticas profissionais, o que demanda que cada área do conhecimento repense sua responsabilidade nessa discussão" (ARAÚJO; SILVA JÚNIOR, 2020, p. 104).

Existem diversas possibilidades de estudos de informação teóricos, metodológicos e práticos com ênfase nas temáticas étnico-raciais, principalmente se fizerem uso de teorias críticas para isso (ARAÚJO; SILVA JÚNIOR, 2020; VELEZ; VILLA-NICHOLAS, 2017). O desenvolvimento dessas pesquisas na Ciência da Informação (Cl) encontra-se em expansão. Mas uma das possibilidades não mencionada pelas autoras, e que será trabalhada neste artigo, é a dos estudos métricos da informação em ciência e tecnologia.

Esse robusto subcampo da $\mathrm{Cl}$, compreendido no âmbito dos estudos da comunicação científica, fornece aos seus estudiosos abordagens, recursos e ferramentas que possibilitam o mapeamento do conhecimento científico e seu desempenho, que pode ser medido dentro e fora da academia, a partir da aplicação de métricas tradicionais baseadas em citação, ou mesmo alternativas, de sua circulação em fontes da web social. 
Como extensão do trabalho apresentado no $7^{0}$ Encontro Brasileiro de Bibliometria e Cientometria (EBBC, ${ }^{1}$ o presente artigo busca investigar a produção e uso do conhecimento científico nos estudos raciais focados nas diásporas 'afro-americana' e 'afro-brasileira' por meio de indicadores bibliométricos e altmétricos, de forma a identificar como as questões étnico-raciais são abordadas na base de dados Dimensions.

\section{A DIÁSPORA COMO ELEMENTO DE PESQUISA E AS TEMÁTICAS ÉTNICO-RACIAIS NA CIÊNCIA DA INFORMAÇÃO}

A palavra "diáspora" costuma estar relacionada à dispersão geográfica motivada por razões políticas ou religiosas e foi aplicada primeiro aos povos gregos no mundo helênico e, mais tarde, aos judeus após a queda de Jerusalém. Passou a ser adotada por estudiosos como ferramenta para analisar a experiência dos afrodescendentes durante o século $X X$, especialmente durante as décadas de 1950 e 1960 (AZEVEDO, 2005).

Atualmente, utiliza-se o conceito de diáspora para todos os povos afrodescendentes que estão espalhados pelo mundo, como uma perspectiva comparativa embutida de pessoas negras dentro e fora da África o que, portanto, permite que os estudiosos tenham uma compreensão abrangente do mundo negro em um determinado momento. Da perspectiva de uma diáspora, aprende-se sobre as semelhanças que ligam e as dessemelhanças que separam as experiências discretas dos negros espalhados pelo globo (AZEVEDO, 2005).

Uma perspectiva diaspórica pode refinar a compreensão das histórias locais, regionais e mundiais, bem como, identificar questões teóricas e metodológicas críticas que irão influenciar as agendas de pesquisa (BYFIELD, 2000). Assim, o modelo de diáspora deve ir além de descobrir semelhanças culturais, dissecando experiências políticas, sociais e econômicas dos negros, correlacionando-as com as de outras diásporas e comunidades, o que permite novos rumos de investigação acadêmica e possibilitam o entendimento acerca das experiências do mundo negro (AZEVEDO, 2005).

A maior parte dos estudiosos africanos e afro-americanos concorda que o conceito de diáspora é a melhor ferramenta acadêmica de análise descoberta, ou recuperada, nas últimas décadas (AZEVEDO, 2005). Considerando essa noção da diáspora como elemento

\footnotetext{
1 SANTOS, S. R. O.; ARAÚJO, R. F. de. Atenção on-line e dados de citação de pesquisas com temáticas étnico-raciais: um comparativo entre publicações sobre afrodescendentes brasileiros e americanos. In: ENCONTRO BRASILEIRO DE BIBLIOMETRIA E CIENTOMETRIA, 7., 2020. Salvador. Anais [...].

Salvador: EDUFBA, 2020. p. 205-211. Disponível em: https://repositorio.ufba.br/ri/handle/ri/32385. Acesso em: 21 set. 2021.
} 
para pesquisa, vê-se o Brasil e os Estados Unidos como dois países emblemáticos. No Brasil, mais da metade da população, cerca de 109 milhões de afro-brasileiros, em torno de 56\% da população, se autodeclara negra - soma de pretos e pardos (IBGE, 2019), a maior população negra de um país fora da África. A segunda maior, encontra-se nos Estados Unidos da América, com mais de 40 milhões de afro-americanos, isto é, cerca de $13 \%$ de pessoas consideradas negras (CENSUS, 2016).

Enquanto o afro-brasileiro encontra seu lugar sem problemas conceituais e territoriais, o mesmo não acontece para o termo afro-americano. Ainda que considerado em si, como impróprio, uma vez que muitas pessoas de ascendência africana moram em países do continente americano e não estão incluídas no termo afro-americano, "o termo tem sido usado para designar afrodescendentes domiciliados nos Estados Unidos desde 1865" (ASANTE, 2005, p. 8). Diversas áreas de conhecimento têm se dedicado aos estudos destas diásporas.

A Ciência da Informação é um campo que se dedica às "questões científicas e à prática profissional voltadas para os problemas da efetiva comunicação do conhecimento e de seus registros entre os seres humanos, no contexto social, institucional ou individual do uso e das necessidades de informação" (SARACEVIC, 1996, p. 47), tendo a "preocupação de esclarecer um problema social concreto, o da informação, e voltada para o ser social que procura informação, coloca-se no campo das ciências sociais, que são o meio principal de acesso a uma compreensão do social e do cultural" (LE COADIC, 2004, p. 21).

Para Araújo (2003), os desdobramentos na maneira como se entende a informação, como algo que é construído socialmente, tem reformulado o entendimento sobre o papel da Ciência da Informação e o paradigma social está na própria concepção do campo, de forma mais precisa, em seus antecessores, a Biblioteconomia e a Documentação (CAPURRO; HJORLAND, 2007).

A Ciência da Informação não aborda apenas a informação, mas os sujeitos que dela necessitam e se apropriam, sendo importante que o trabalho com os mesmos não desconsidere as questões sociais intrínsecas à sua realidade. Sendo assim, considera-se que "enquanto a Cl não for percebida com ênfase na conotação social, suas contribuições por meio da produção intelectual ou científica de seus profissionais não terão impacto na conjuntura coletiva" (GARCIA; TARGINO; DANTAS, 2012, p. 6). Nesse cenário, reforça-se o quão urgente se torna a reflexão sobre como o campo dialoga com as temáticas e relações étnico-raciais. 
Em 1996, nos Estados Unidos, Peterson (1996) já se questionava o que era necessário para que a Biblioteconomia e seus profissionais levassem a sério os estudos raciais. A autora afirma que já existiam, àquela época, trabalhos sobre raça e racismo na área, mas que eles não receberam a atenção séria que mereciam. Isto porque consideravase que os trabalhos sobre a temática derivavam de características e experiências pessoais, ao invés de reconhecer o rigor intelectual, a integridade e a autoridade presentes nesses estudos (PETERSON, 1996).

Honma (2005) afirma ser necessário criticar e desafiar as ideologias prevalecentes que tratam o assunto de "raça" como algo fora do escopo de investigação científica da Biblioteconomia. Sob a justificativa de ser uma área diversa ou que apoia a multiculturalidade, vê-se temas relacionados à diversidade, especificamente sobre raça, sendo tratados de forma acrítica ou não sendo tratados de nenhuma forma (HUDSON, 2017). Enquanto essas discussões não são desenvolvidas, tópicos relacionados à diversidade, raça e etnia continuarão a permear a Biblioteconomia e a Ciência da Informação, envolvendo profissionais e pesquisadores da área em conversas vazias e sem contribuição para ação (COOKE, 2018).

Neste sentido, é preciso romper com essas narrativas neutras de raça nas pesquisas da área da informação (HONMA, 2005). Já existe um crescente corpo de trabalhos que busca fazer isso, reorientando os Estudos da Informação para centralizar nas discussões sobre raça e racismo. A exemplo disso, tem-se a edição do periódico Library Trends (v. 67, n. 1, 2018), "Race and Ethnicity in Library and Information Science: An Update", que revisita as discussões que começaram nos anos 2000 sobre as relações étnico-raciais e atualiza vários outros artigos seminais publicados naquela época, com o intuito de avaliar o status de raça e etnia na Biblioteconomia e Ciência da Informação, cerca de vinte anos depois, e incitar os leitores e profissionais da informação a ações e defesa da justiça social (COOKE, 2018).

Outra iniciativa, foi a chamada de artigos para compor o número especial "Information Studies, Race and Racism" do periódico Open Information Science, com a finalidade de evoluir o campo com uma fundamentação teórica mais crítica, que se afasta de uma ideologia "sem cor" e das narrativas de neutralidade, que só servem para disfarçar a onipresença da branquitude. Entre as abordagens e estudos sugeridos em estudos da informação relacionados à raça e ao racismo, estão: métodos antirracistas em estudos de informação; teoria crítica da raça e estudos de informação; análise interseccional de estudos da informação (raça e gênero, sexualidade, classe, deficiência e capacitismo, indigeneidade); análise de branqueamento em organizações e instituições de informação; debates 
contemporâneos ou históricos sobre raça e/ou racismo em instituições de informação (bibliotecas, arquivos, museus, coleções especiais, etc.); Big Data, raça e racismo; raça, racismo e organização do conhecimento; informação, vigilância e racismo (ARAÚJO; SILVA JúNIOR, 2020).

Conforme exposto, são abundantes as possibilidades e abordagens que podem ser empregadas no estudo das temáticas étnico-raciais na Biblioteconomia e Ciência da Informação, e não se esgotam no exposto pelas autoras. Embora ações como essas estejam ganhando espaço, a crítica de Peterson (1996) continua válida: se o estudo das relações étnico-raciais fosse mesmo levado a sério, a comunidade científica da área reconheceria a oportunidade de crescimento e de produção de novos conhecimentos, investindo recursos em estudos sobre o tópico, bem como, em tempo para a realização de trabalhos profundos, analíticos e inovadores.

No Brasil, vê-se nos últimos anos um movimento crítico crescente pela discussão das temáticas étnico-raciais e a luta antirracista no campo da Biblioteconomia e Ciência da Informação. Em 2018, por exemplo, foi lançado o livro Bibliotecári@s Negr@s: ação, pesquisa e atuação política, publicado pela Associação Catarinense de Bibliotecários (ACB), com ricas discussões que buscam adicionar uma camada de representatividade e protagonismo negro no fazer bibliotecário, ressaltando que esses profissionais existem e ocupam espaços de pesquisa, atuação e militância (SILVA; LIMA, 2018).

Em 2019, sob o Selo Nyota, foi publicada a coletânea Mulheres Negras na Biblioteconomia, com o objetivo de refletir sobre as interseções entre as relações raciais, gênero e informação. A obra busca contribuir para o crescente movimento de pesquisadoras e pesquisadores negros de demarcar e fortalecer o seu espaço na Biblioteconomia e na Ciência da Informação (SILVA, 2019). Também em 2019, o selo publicou o livro Epistemologias Negras: relações raciais na Biblioteconomia, que apresenta produções com narrativas de intelectuais negros da área tendo como centralidade a epistemologia negra e o enfrentamento de questões sociais e políticas no fazer científico e profissional (BARROSO et al., 2019).

Para além das publicações científicas, destaca-se que em julho de 2020, foi criado o Grupo de Trabalho Relações Étnico-Raciais e Decolonialidades (GT-RERAD) vinculado à Federação Brasileira de Associações de Bibliotecários, Cientistas da Informação e Instituições (FEBAB), que se propõe a 
discutir e realizar ações em prol da promoção da diversidade étnico-racial, emancipação de povos em vulnerabilidade econômica, social e educacional por intermédio do acesso à informação e às bibliotecas, bem como refletir sobre a decolonização do ensino e prática em Biblioteconomia em solo brasileiro (RERAD, 2020).

Essas iniciativas demarcam um movimento legítimo para fortalecer o espaço de pesquisadores e profissionais negros na Biblioteconomia e na Ciência da Informação, promovendo a reflexão sobre as relações raciais com vistas a consolidar a importância da luta antirracista e o respeito à diversidade étnico-racial e cultural.

A área também registra alguns trabalhos, mais especificamente, no campo dos estudos métricos da informação, que buscaram mensurar a produção científica sobre as relações étnico-racias (VALÉRIO; BERNARDINO; SILVA, 2012; ORTOLAN et al., 2015; ARTES; MENA-CHALCO, 2017).

Por meio de um estudo cientométrico, Valério, Bernardino e Silva (2012) analisam a produção científica que versa sobre as questões raciais, especialmente a população afrodescendente, nos anais do Encontro Nacional de Pesquisa em Ciência da Informação (ENANCIB) nos anos de 2005-2010 e percebem, com os resultados, que poucos são os trabalhos que tratam de questões raciais, com ênfase na população negra.

Com o objetivo de averiguar, por meio de publicações científicas, as características da abordagem da temática sobre o negro em Ciência da Informação no Brasil, Ortolan e outros (2017) investigam por meio de uma abordagem bibliométrica esta produção presente na Base de Dados Referenciais de Artigos de Periódicos em Ciência da Informação - BRAPCI. Os autores analisaram essa produção por meio do estudo dos autores e revistas que mais publicaram sobre a temática do negro na literatura científica brasileira em Ciência da Informação e, ainda, as palavras-chave mais frequentes relacionadas à temática.

Por fim, Artes e Mena-Chalco (2017) analisaram a evolução dos estudos sobre relações raciais considerando como fonte de dados os trabalhos de mestrado e doutorado defendidos nas instituições brasileiras e registradas no banco de teses e dissertações da Coordenação de Aperfeiçoamento de Pessoal de Nível Superior (Capes). Por meio da definição de 191 descritores, os autores caracterizaram informações dos registros das teses e dissertações no período de 25 anos (1987-2011). Ao todo foram identificados 4.204 trabalhos sobre a temática, defendidos em oitocentos programas de pós-graduação de 161 universidades ou instituições de pesquisa e as mulheres são maioria nas produções identificadas na temática das relações raciais no Brasil (ARTES; MENA-CHALCO, 2017). 


\section{PERCURSO METODOLÓGICO}

A pesquisa possui abordagem exploratória, de caráter quantitativo e descritivo. Grande parte da pesquisa social é realizada buscando explorar um tópico. Essa abordagem normalmente é empregada quando um pesquisador examina um novo interesse ou quando o assunto de estudo em si é relativamente novo. O recurso descritivo, por sua vez, permite pormenorizar as observações científicas acerca do assunto de forma deliberada e cuidadosa (BABBIE, 2010).

O delineamento do percurso metodológico da pesquisa é representado na Figura 1 e, logo após, os procedimentos são detalhados.

Figura 1 - Delineamento dos procedimentos metodológicos

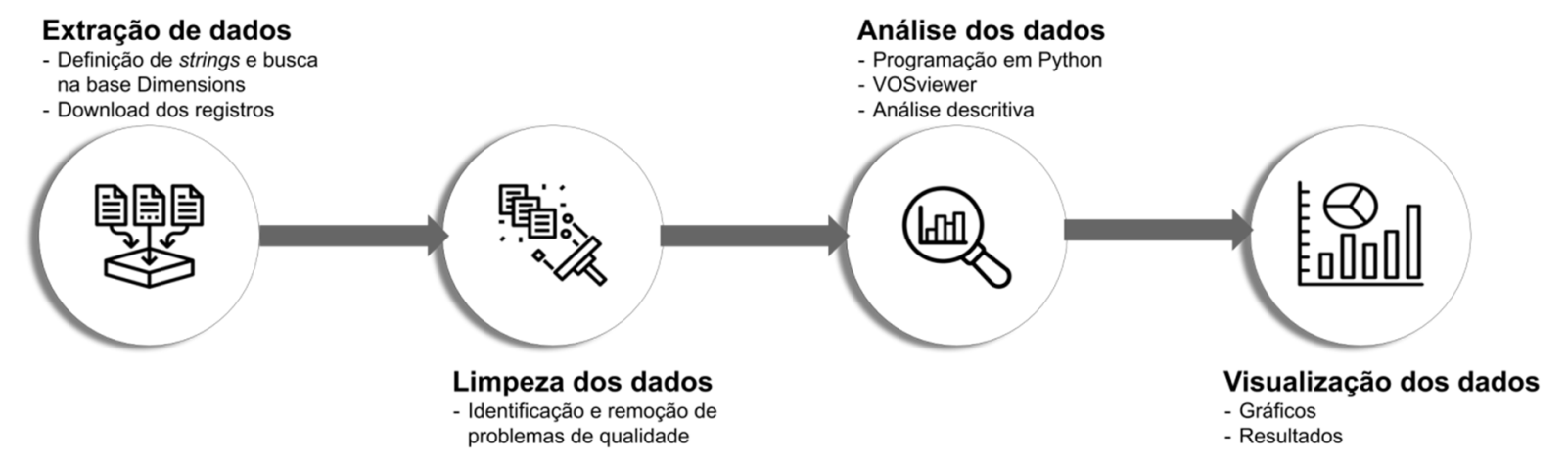

Fonte: elaborado pelos autores (2020).

A coleta dos dados foi realizada no dia 30 de outubro de 2020 via Dimensions Plus (https://app.Dimensions.ai) que fornece acesso ao conjunto completo, abrangente e conectado de registros da base Dimensions, abrangendo publicações, concessões, patentes, ensaios clínicos, dentre outros. A base foi escolhida por ser considerada uma alternativa à Scopus e à Web of Science, sendo ainda mais abrangente que estas (THELWALL, 2018), e por apoiar a diversidade nas métricas de avaliação da produção científica, inclusive apresentando dados altmétricos (HOOK; PORTER; HERZOG, 2018).

Para escolha dos termos de busca, a pesquisa trabalhou com descritores relacionados às temáticas étnico-raciais apresentados no estudo de Artes e Mena-Chalco (2017), considerando entre eles os que obtiveram mais resultados de busca. A partir desse critério, a string ("afrodescendente" $O R$ negro $O R$ negra $O R$ negritude $O R$ afrobrasileiro) AND 
("brasileiro" OR "brasileira") foi utilizada para as buscas em português e ("african american" AND black) para as buscas em inglês. A comparação entre a produção sobre negros do Brasil e dos Estados Unidos se dá pelo fato destes serem os países com maior população negra em diáspora (ASANTE, 2005), possibilitando a construção de paralelos e verificação de dissonâncias na análise da produção científica.

O tipo de publicação selecionado para análise foi de artigos, limitando-se a busca das expressões presentes no título e no resumo. Não houve restrição quanto à área de conhecimento na qual os artigos foram publicados de forma a verificar como a temática é abordada nos trabalhos recuperados na base de dados. A exportação dos dados da busca na Dimensions Plus, no formato de planilhas (.csv) para mapeamento bibliométrico, foi limitada a 2500 linhas. Considerando a quantidade de registros recuperados em português, 2063, optou-se por trabalhar com 2000 registros, tanto em português, quanto em inglês. A base de dados ordena os resultados de busca por relevância, data de publicação, taxa de citações relativas (RCR), taxa de citação do campo (FCR), citações ou score altmétrico. De forma a restringir o escopo da amostra, foram selecionados os 2000 registros ordenados pelo score altmétrico <Sort by: Altmetric Attention Score>.

Sud e Thelwall (2013) apresentam a Altmetria como uma forma de mensurar a atenção que artigos estão recebendo na web social, quando é endossado ou, pelo menos, mencionado nas redes, uma vez que as citações formais levam certo tempo para serem indexadas. Para os autores, os dados altmétricos podem afetar os dados de citação e viceversa.

Após a coleta de dados, procedeu-se à limpeza destes, caracterizada pela identificação de problemas de qualidade nos registros baixados. Foram localizadas algumas inconsistências nos metadados que impossibilitavam a análise no VOSviewer, como espaços e vírgulas que alteravam o formato da planilha. No caso das planilhas sobre afrobrasileiros, foi necessária, também, a remoção de acentuação e normalização do texto para letras minúsculas, casos que poderiam interferir na análise. A partir dessa organização, as planilhas foram inseridas no software a fim de gerar visualizações de co-ocorrência de termos nos títulos das publicações sobre afro-brasileiros e afro-americanos, por meio de clusters.

Para a análise e criação dos gráficos temporal e altmétrico, utilizou-se a linguagem de programação Python, versão 3.8.3. Para obtenção dos dados altmétricos a API do Altmetric foi empregada, uma vez que esta permite a coleta e reunião de dados em forma tabular a partir do DOI das publicações. A análise e descrição dos dados das publicações são apresentadas a partir da sua distribuição por data de publicação, co-ocorrência de termos e 
desempenho de citações (quantas vezes os trabalhos foram citados, de acordo com dados da planilha) e dados altmétricos de atenção on-line.

\section{ANÁLISE E DISCUSSÃO DOS RESULTADOS}

Os registros recuperados compõem um corpus de 4 mil artigos, sendo 2 mil sobre afro-brasileiros e os outros 2 mil sobre afro-americanos. As publicações compreendem o período entre 1970 e 2020. No Gráfico 1, apresenta-se o crescimento da discussão sobre a temática na literatura ao longo do período delimitado.

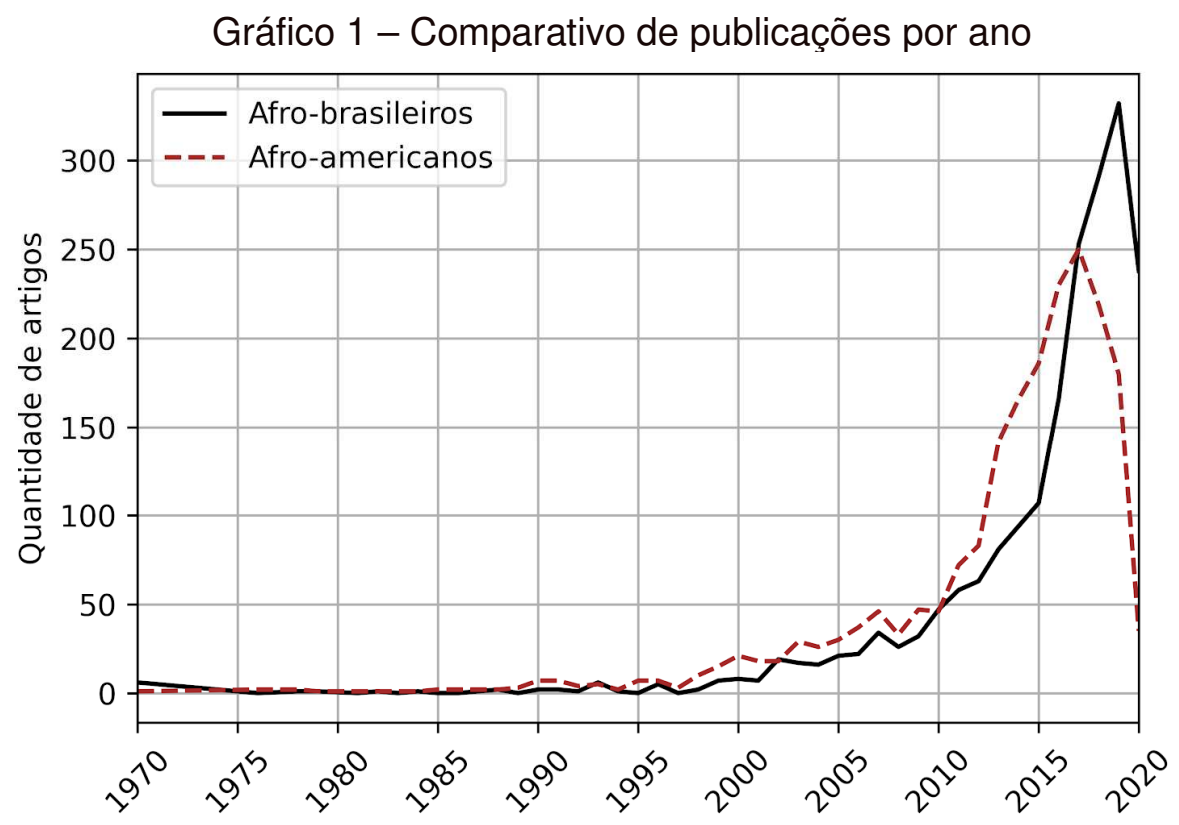

Fonte: elaborado pelos autores (2020).

Apesar de existirem publicações esporádicas desde 1970, a literatura sobre temáticas étnico-raciais só começa a ganhar tração a partir dos anos 1990. Müller (2015) aponta que existia uma invisibilidade da temática antes dos anos 2000 no caso de publicações sobre afro-brasileiros. O que se evidenciou, também, no caso das publicações sobre afro-americanos.

Não há como afirmar, de fato, o que levou ao aumento da produção científica sobre o tema nos anos 2000. No caso brasileiro, o crescimento pode estar associado à ampliação do acesso da população negra ao ensino superior, como apontam Artes e Mena-Chalco (2017). O acesso à educação por parte dessa população, por sua vez, deriva das reivindicações do movimento negro no Brasil que foram capazes de influenciar o governo brasileiro e promover mudanças dentro de vários setores, sobretudo, nas universidades 
públicas, com o processo de implementação de políticas de ações afirmativas voltadas para a população negra (GOMES, 2011).

A partir de uma análise de co-ocorrência de termos baseada nos títulos dos artigos, criou-se um mapa para identificar possíveis temáticas mais frequentes nas pesquisas sobre afrodescendentes. Na Figura 2, são apresentados seis clusters que indicam as temáticas abordadas nos trabalhos sobre afro-brasileiros e analisaremos as cinco principais.

Figura 2 - Coocorrência de termos nos títulos das publicações sobre afro-brasileiros

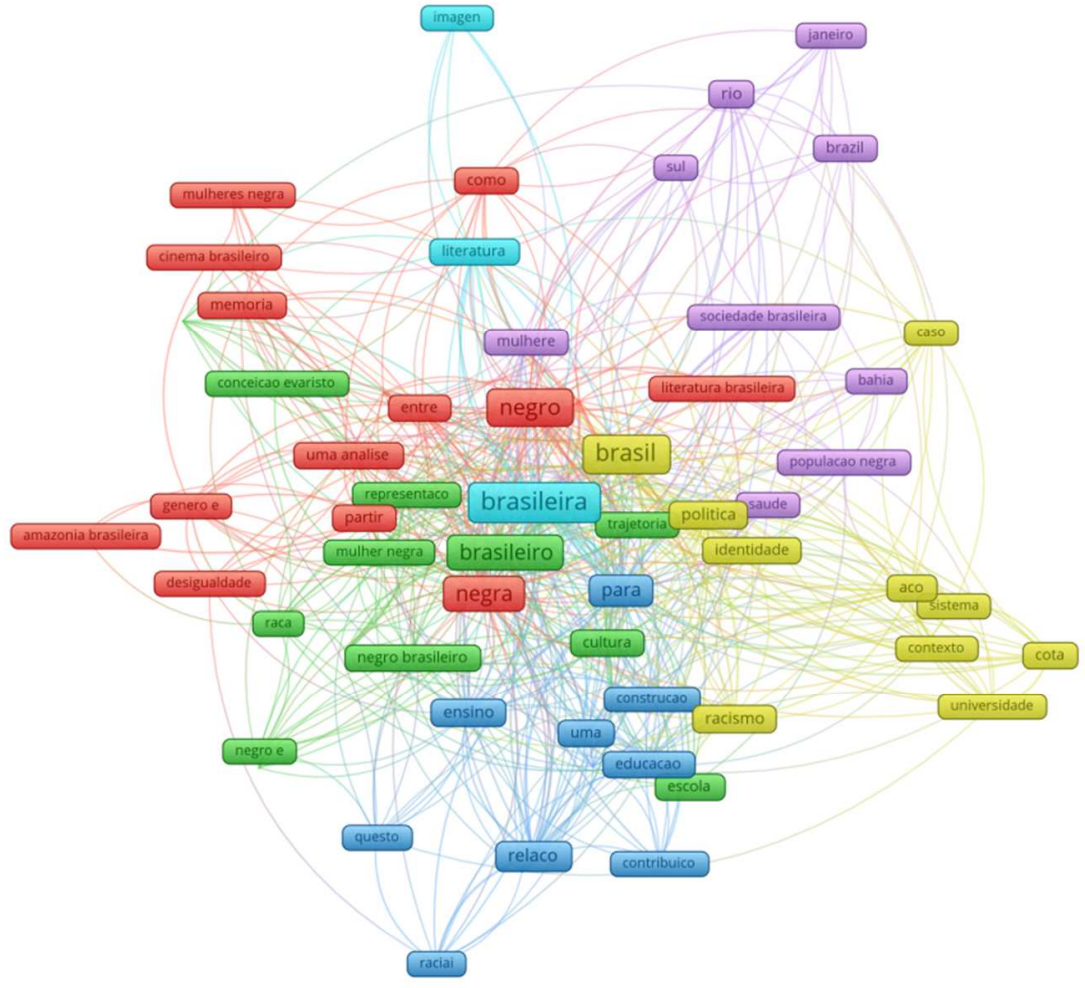

Fonte: elaborado pelos autores no VOSviewer (2020).

Esse tipo de visualização permite descrever o que os clusters têm em comum, como por exemplo a ênfase das pesquisas. Dessa forma, identifica-se no cluster vermelho (o principal) a relação entre afrodescendência e gênero, abordando as mulheres negras nas artes e no cinema brasileiro, listando, ainda, a desigualdade entre homens e mulheres negras e a memória afro-brasileira.

O cluster verde tem a autora Conceição Evaristo como foco e a representação da mulher negra na literatura, bem como sua autorrepresentação na escrita. Fala-se, aqui, em "Escrevivência", isto é, a escrita baseada no cotidiano, na experiência de vida e nas lembranças da própria autora e do seu povo (BISPO; LOPES, 2018). 
O cluster azul escuro, por sua vez, indica que as pesquisas se concentram na discussão racial em torno do ensino e da educação. Santos e Araújo (2020) identificaram que cerca de $20 \%$ dos trabalhos sobre afro-brasileiros tinham como campo de pesquisa principal os estudos em Educação. Já Artes e Mena-Chalco (2017) perceberam a Educação como área de maior participação de trabalhos na temática de relações raciais em teses e dissertações produzidas no país. As discussões das pesquisas no cluster giram, dentre outros aspectos, em torno da obrigatoriedade do ensino da "História e Cultura AfroBrasileira" estabelecida pela Lei 10.639, de 9 janeiro de 2003, dificuldades e iniciativas para implementação das diretrizes propostas (BRASIL, 2003).

Enquanto no Brasil ainda se fala nas conquistas do sistema de cotas no Ensino Superior e os desafios da aplicação da lei para que o ensino da História e Cultura AfroBrasileira seja implementado nas escolas, o acesso ao Ensino Superior nos Estados Unidos ocorria, em grande parte, por meio de universidades historicamente negras. De acordo com Kim e Conrad (2006), até metade do século XX, mais de 90\% dos estudantes afroamericanos matriculados no Ensino Superior foram educados em universidades e faculdades historicamente negras (Historically Black Colleges and Universities - HBCUs). Embora isso esteja mudando desde 1960, devido a pressões para cancelar a segregação nessas instituições, não se pode negar as contribuições históricas para a inserção da população negra afro-americana no Ensino Superior. Nesse sentido, e como será visto adiante, as discussões sobre a inserção da população negra nessa modalidade de ensino aparenta estar, em parte, resolvida.

O cluster amarelo, destaca a questão do racismo e como seu combate no contexto brasileiro está atrelado aos aspectos de políticas públicas como as de acesso ao ensino superior, considerando, principalmente, questões relacionadas ao sistema de cotas raciais nas universidades brasileiras.

O cluster roxo, menos representativo, discute questões de saúde da população negra na sociedade brasileira, considerando as diferentes perspectivas nos estados brasileiros, como a Bahia e o Rio de Janeiro. No estudo de Artes e Mena-Chalco (2017), as áreas de Medicina e Saúde coletiva também foram as menos representativas quanto aos trabalhos da pós-graduação defendidos no país. Essa talvez seja uma das maiores diferenças entre as temáticas das pesquisas afro-brasileiras, quando comparadas com as afro-americanas. Na Figura 3, estão os termos presentes nas publicações sobre afro-americanos e suas relações. De forma geral, nota-se que a saúde da população negra perpassa todos os clusters. 
Santos e Araújo (2020) identificaram que os trabalhos que mais abordaram os afrodescendentes americanos estavam relacionados a esse tema, como "Saúde Pública e Serviços de Saúde" e "Ciências Clínicas".

Figura 3 - Coocorrência de termos nos títulos das publicações sobre afro-americanos

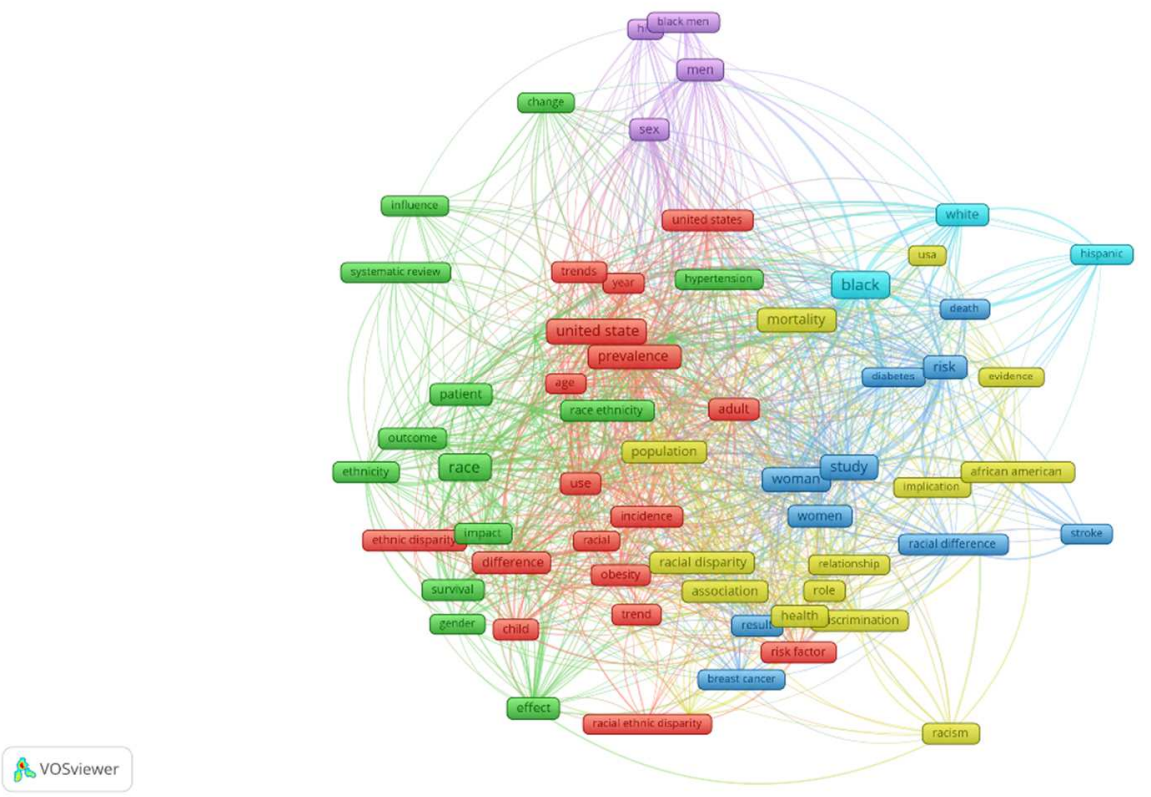

Fonte: elaborado pelos autores no VOSviewer (2020).

Os artigos sobre afro-americanos que tratam da saúde, o fazem focando nas diferenças raciais entre os pacientes ou em como as doenças afetam de forma diversa a população negra, como pode ser observado em todos os clusters.

O cluster verde, por exemplo, agrupa pesquisas que discutem a etnicidade e gênero a partir de doenças como hipertensão e o seus efeitos e impactos em pacientes negros. As pesquisas localizadas no cluster vermelho, por sua vez, abordam o tratamento de doenças, como a obesidade, e a incidência delas em crianças e adultos negros.

O cluster azul escuro trata de estudos sobre mulheres negras e doenças crônicas como câncer de mama, diabetes e fatalidades como derrames, sendo que todas elas centralizam a discussão nas disparidades raciais. De acordo com Austin e Harris (2011), o Healthy People 2010, programa de metas para promoção da saúde e prevenção de doenças nos Estados Unidos, identificou a necessidade de abordar as disparidades de saúde entre afro-americanos e outras populações como asiáticos, hispânicos e indígenas americanos. Esses são grupos desproporcionalmente afetados por câncer, doenças cardiovasculares, diabetes, infecção por HIV e AIDS, como pode ser observado no cluster roxo, que relaciona os termos homens negros, sexo e HIV. 
No cluster amarelo as pesquisas discutem o papel do racismo e da discriminação no atendimento à população negra e como ele podem estar associados às taxas de mortalidade de negros no país. E no cluster azul claro, a questão da saúde é debatida a partir de análises, ensaios e comparações entre negros, hispânicos e brancos. Nesse sentido, Austin e Harris (2011) afirmam que já é possível identificar um crescente corpo de pesquisas sobre disparidades de saúde e intervenções eficazes, o que se evidenciou no mapa.

Para além das orientações temáticas, a presente pesquisa buscou analisar 0 desempenho das mesmas por meio de um olhar comparativo do impacto das publicações sobre afro-brasileiros e afro-americanos, no que concerne aos dados altmétricos e de citação (Grafico 2). Em seguida, os dados altmétricos são detalhados e demonstram a distribuição entre as mídias sociais com mais impacto (Gráfico 3).

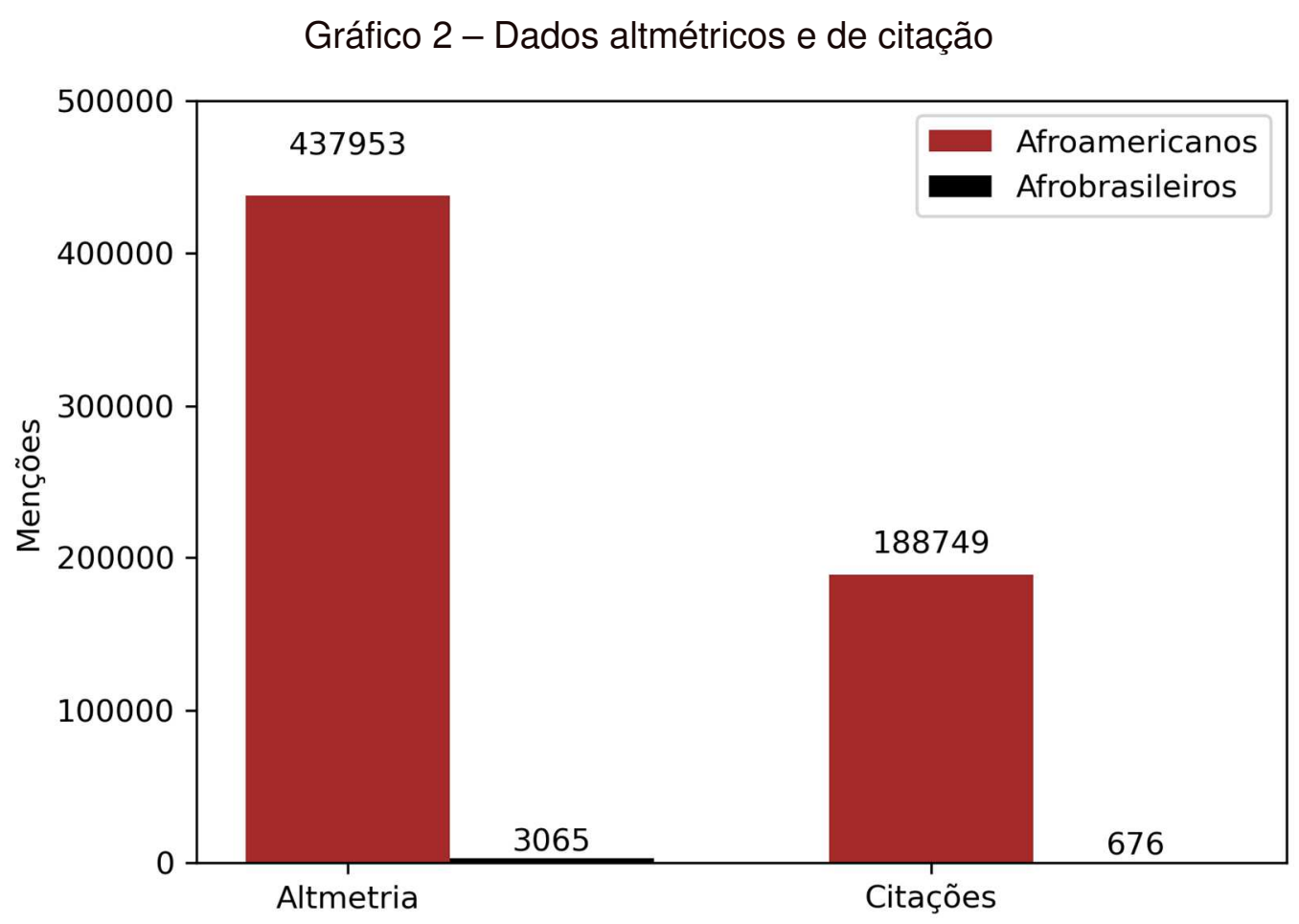

Fonte: elaborado pelos autores (2020).

Sud e Thelwall (2013) apresentam a Altmetria como uma forma de mensurar a atenção que artigos estão recebendo na web social, quando é endossado ou, pelo menos, mencionado nas redes, uma vez que as citações formais levam certo tempo para serem indexadas. Para os autores, os dados altmétricos podem afetar os dados de citação e viceversa. No presente artigo, considera-se a quantidade de citações que um trabalho recebe 
como "uso", pois entende-se que houve efetivo uso da publicação na produção de novas pesquisas. A "atenção on-line", por sua vez, é mensurada pela quantidade de publicações nas mídias sociais.

O grande contraste entre os dados de altmetria e de citação das publicações sobre os afrodescendentes brasileiros e estadunidenses pode ser considerado um reflexo das diferenças na comunicação científica e das tradições de pesquisa, tanto na comparação Estados Unidos e Brasil, sendo necessário destacar a questão do idioma (THELWALL et al., 2013), quanto na comparação Ciências da Saúde e Ciências Sociais/Humanidades (MEADOWS, 1999).

As citações apontam um reconhecimento formal das publicações, ressaltando a quantidade de vezes que os trabalhos foram citados em outros trabalhos. As métricas alternativas, por sua vez, fornecem uma forma de "monitoramento quanto ao interesse e relevância do conteúdo publicado ao longo do tempo" (GOUVEIA, 2013, p. 224). Identificase, assim, que as publicações sobre temáticas étnico-raciais atraem grande interesse, mesmo que este não se converta imediatamente em citações. Thelwall et al. (2013) apontam que existem relações significativas entre pontuações altas de dados altmétricos e citações mais altas para artigos.

Gráfico 3 - Distribuição dos dados altmétricos

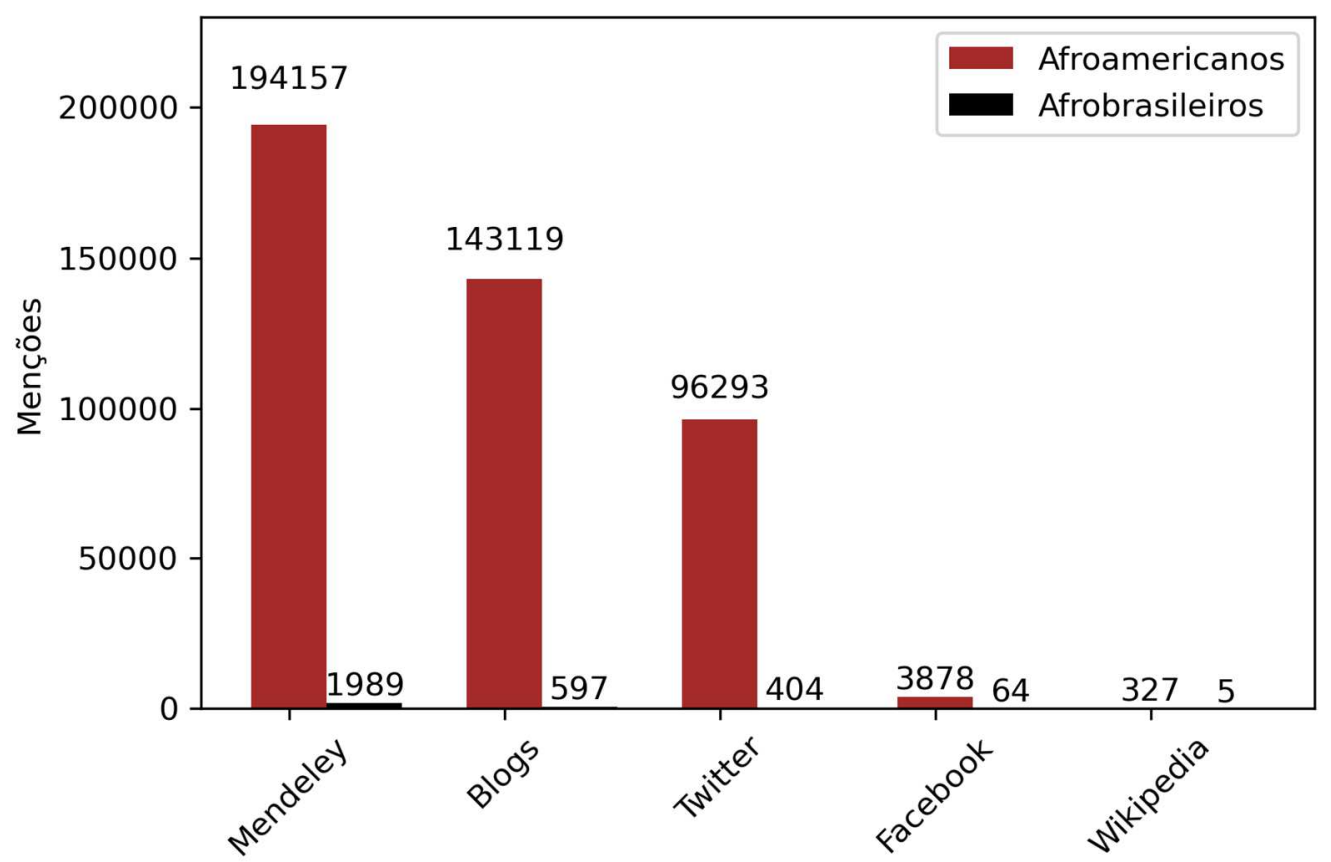

Fonte: elaborado pelos autores (2020). 
Quanto aos dados altmétricos, identificou-se a distribuição da atenção on-line entre as mídias sociais: Mendeley, Blog, Twitter, Facebook e Wikipedia. O Mendeley computa os "leitores" do artigo, quer dizer, a quantidade de usuários que salvaram artigos sobre a temática em sua biblioteca digital, não necessariamente aqueles que leram os trabalhos.

De toda forma, pela quantidade assinalada, pode-se verificar o interesse pela temática. Postagens em blogs aparecem em segundo lugar, seguidos do Twitter, Facebook e Wikipedia. Apesar de o Twitter ser considerado como a principal fonte de dados altmétricos (THELWALL et al., 2013), observa-se aqui que os dados de leitores no Mendeley e os dados de citações em blogs se sobressaíram para as publicações sobre afrodescendentes.

\section{CONSIDERAÇÕES FINAIS}

Os resultados relatados apontam que a temática das relações étnico-raciais, especificamente sobre afrodescendentes americanos e brasileiros está em constante desenvolvimento. As publicações sobre afro-brasileiros estão localizadas nas áreas das humanidades, dando ênfase às discussões sobre representação da mulher negra na literatura, as conquistas do sistema de cotas no Ensino Superior e os desafios da aplicação da lei para que o ensino da História e Cultura Afro-Brasileira seja implementado nas escolas, o que não acontece na produção científica sobre afro-americanos. Os estudos sobre afroamericanos concentram-se, principalmente, na área da saúde, com foco nas disparidades raciais entre negros e outras populações.

Observou-se, assim, focos diferentes entre as publicações, embora o tema saúde tenha perpassado as duas populações; em menor quantidade no caso do Brasil. Identificamos, ainda, o predomínio das publicações em inglês nos quesitos de citações e menções na web social. Os dados altmétricos e de citação indicam que as temáticas étnicoraciais atraem o interesse dentro e fora da academia, no primeiro caso indicado pelos dados de leitores no Mendeley, uma rede social acadêmica, e, no segundo, pelas redes sociais Twitter e Facebook, utilizadas tanto por cientistas, quanto por cidadãos comuns.

Conforme apontado, as relações raciais têm potencial para serem abordadas sob múltiplos enfoques, nas mais diversas áreas do conhecimento. Os Estudos Métricos da Informação evidenciam oportunidades para o desenvolvimento de pesquisas que contribuam para a análise da produção científica sobre esse tópico e o impacto que ela causa no meio acadêmico e social, lançando luz sobre um corpo de conhecimento que tem a capacidade de conectar, transformar e empoderar toda uma população. Os pesquisadores e profissionais 
negros da Biblioteconomia e da Ciência da Informação, de forma mais ampla, possuem um vasto campo para realização de pesquisas e construção do conhecimento científico decolonilizado, não apenas considerando a população negra como objeto de estudo, mas também como sujeitos de suas próprias narrativas.

\section{REFERÊNCIAS}

ARAÚJO, C. A. A. A Ciência da Informação como ciência social. Ciência da informação, v. 32, n. 3, p. 21-27, 2003. Disponível em: http://revista.ibict.br/ciinf/article/view/985. Acesso em: 01 nov. 2020.

ARAÚJO, R. F.; SILVA JÚNIOR, J. F. Blackfishing e a Transformação Transracial Monetizada. In: SILVA, T. Comunidades, Algoritmos e Ativismos: olhares afrodiaspóricos. São Paulo: LiteraRua, 2020.

ARTES, A.; MENA-CHALCO, J. Expansão da temática relações raciais no banco de dados de teses e dissertações da Capes. Educação e Pesquisa, São Paulo, v. 43, n. 4, p. 1221-1238, out./dez. 2017. Disponível em: https://doi.org/10.1590/s15179702201702152528

ASANTE, M. K. African Americans. 2005. p. 8-14. In: ASANTE, M. K.; MAZAMA, A. (ed.). Encyclopedia of Black studies. Thousand Oaks, CA: Sage Publications, 2005.

AUSTIN, S.; HARRIS, G. Addressing Health Disparities: The Role of an African American Health Ministry Committee. Social Work in Public Health, v. 26, n. 1, p. 123-135, 2011. Disponível em: https://doi.org/10.1080/10911350902987078. Acesso em: 30 nov. 2020.

AZEVEDO, M. J. Diaspora. 2005. p. 216-219. In: ASANTE, M. K.; MAZAMA, A. (ed.). Encyclopedia of Black studies. Thousand Oaks, CA: Sage Publications, 2005.

BABBIE, E. R. The practice of social research. 12. ed. Belmont: Cengage Learning, 2010.

BALDERRAMA, S. R. This Trend Called Diversity. Library Trends, v. 49, n. 1, 2000, p. 194-214. Disponível em: https://www.ideals.illinois.edu/handle/2142/8331. Acesso em: 31 out. 2020.

BARROSO, D. et al (org.). Epistemologias negras: relações raciais na Biblioteconomia. Florianópolis: Rocha Gráfica e Editora, 2019.

BISPO, E. F.; LOPES, S. A. T. Escrevivência: perspectiva feminina e afrodescendente na poética de Conceição Evaristo. Revista Língua\&Literatura, v. 35, n. 20, p. 186-201, 2018. Disponível em:

http://www.revistas.fw.uri.br/index.php/revistalinguaeliteratura/article/view/2598. Acesso em: 30 nov. 2020.

BRASIL. Presidência da República. Lei no 10.639, de 9 de janeiro de 2003. Altera a Lei no 9.394, de 20 de dezembro de 1996, que estabelece as diretrizes e bases da educação nacional, para incluir no currículo oficial da Rede de Ensino a obrigatoriedade da temática 
"História e Cultura Afro-Brasileira", e dá outras providências. Brasília, DF: Presidência da República, 2003. Disponível em:

http://www.planalto.gov.br/ccivil_03/leis/2003/l10.639.htm. Acesso em: 30 nov. 2020.

BYFIELD, J. Rethinking the African diaspora. African Studies Review, v. 43, n. 1, p. 1-9, 2000. Disponível em: https://www.cambridge.org/core/journals/african-studies-

review/article/rethinking-the-african-diaspora/D7A8A527083EC0082509E4D632A0EB70. Acesso em: 31 out. 2020. DOI: https://doi.org/10.1017/S0002020600036271

CAPURRO, R.; HJORLAND, B. O conceito de informação. Perspectivas em Ciência da Informação, Belo Horizonte, v. 12, n. 1, p. 148-207, abr. 2007. Disponível em:

http://www.scielo.br/scielo.php?script=sci_arttext\&pid=S1413-

99362007000100012\&lng=en\&nrm=iso. Acesso em: 01 nov. 2020.

CENSUS United States Census Bureau. Race. 2016. Disponível em:

https://data.census.gov/cedsci/table?q=B02001\&tid=ACSDT1Y2016.B02001\&hidePreview =true. Acesso em: 01 nov. 2020.

COOKE, N. A. Introduction. Library Trends, v. 67 n. 1, p. 1-7, 2018. Disponível em: https://muse.jhu.edu/article/706984. Acesso em: 31 out. 2020. Disponível em: doi:10.1353/lib.2018.0021.

GARCIA, J. C. R.; TARGINO, M. G.; DANTAS, E. R. F. Conceito de responsabilidade social da Ciência da Informação. Informação \& Informação, Londrina, v. 17, n. 1, p. 125, 2012. Disponível em:

http://www.uel.br/revistas/uel/index.php/informacao/article/view/12309. Acesso em: 31 out. 2020.

GOMES, N. L. O movimento negro no Brasil: ausências, emergências e a produção dos saberes. Política \& Sociedade, v. 10, n. 18, p. 133-154, 2011. Disponível em: https://doi.org/10.5007/2175-7984.2011v10n18p133. Acesso em: 30 nov. 2020.

HONMA, T. Trippin'over the color line: The invisibility of race in library and information studies. InterActions: UCLA journal of education and information studies, v. 1, n. 2, 2005. Disponível em: https://escholarship.org/uc/item/4nj0w1mp. Acesso em: 01 nov. 2020.

HOOK, D. W.; PORTER, S. J.; HERZOG, C. Dimensions: Building Context for Search and Evaluation. Frontiers in Research Metrics and Analytics, v. 3, n. 23, aug. 2018. Disponível em: https://doi.org/10.3389/frma.2018.00023. Acesso em: 30 nov. 2020.

HUDSON, D. J. On "diversity" as anti-racism in library and information studies: A critique. Journal of Critical Library and Information Studies, v. 1, n. 1, 2017. Disponível em: http://journals.litwinbooks.com/index.php/jclis/article/view/6. Acesso em: 01 nov. 2020.

IBGE. Pesquisa Nacional por Amostra de Domicílios Contínua trimestral. 2019. Disponível em: https://sidra.ibge.gov.br/tabela/6403. Acesso em: 01 nov. 2020.

KIM, M. M.; CONRAD, C. F. The impact of historically Black colleges and universities on the academic success of African-American students. Research in Higher Education, $v$. 47, n. 4, p. 399-427, 2006. Disponível em: https://doiorg.ez27.periodicos.capes.gov.br/10.1007/s11162-005-9001-4. Acesso em: 21 set. 2021. 
LE COADIC, Y. A ciência da informação. 2. ed. Brasília: Briquet de Lemos, 2004.

MULLER, T. M. P. As pesquisas sobre o "estado do conhecimento" em relações étnicoraciais. Revista do Instituto de Estudos Brasileiros, São Paulo, n. 62, p. 164-183, dez. 2015. DOI: 10.11606/issn.2316-901X.v0i62p164-183. Disponível em: http://www.scielo.br/scielo.php?script=sci_arttext\&pid=S0020$38742015000300164 \&$ Ing=en\&nrm=iso. Acesso em: 30 out. 2020.

ORTOLAN, L. P. V. et al. As temáticas sobre o negro na Ciência da Informação brasileira. Biblionline, João Pessoa, v. 13, n. 3, p. 14-29, jul./set. 2017. Disponível em: https://periodicos.ufpb.br/index.php/biblio/article/view/35715/0. Acesso em: 03 nov. 2020.

PETERSON, L. Alternative perspectives in library and information science: issues of race. Journal of Education for Library and Information Science, v. 37, n. 2, p. 163-174, 1996. DOI 10.2307/40324271. Disponível em: https://www.jstor.org/stable/40324271. Acesso em: 04 ago. 2020.

RERAD. Grupo de Trabalho de Relações Étnico-raciais e Decolonialidades. 2020. Disponível em: https://www.acoesfebab.com/etnico. Acesso em: 15 dez. 2020.

SARACEVIC, T. Ciência da informação: origem, evolução e relações. Perspectivas em Ciência da Informação, Belo Horizonte, v. 1, n. 1, p. 41-62, jan./jun. 1996. Disponível em: http://portaldeperiodicos.eci.ufmg.br/index.php/pci/article/view/235. Acesso em: 01 nov. 2020.

SANTOS, T. H. N.; AQUINO, M. A. Entre os estudos culturais e a Ciência da Informação: fontes de informação étnico-raciais. Informação \& Informação, Londrina, v. 21, n. 1, p. 29-55, 2016. Disponível em: http://www.uel.br/revistas/uel/index.php/informacao/article/view/17492. Acesso em: 30 nov. 2020.

SANTOS, S. R. O.; ARAÚJO, R. F. Atenção on-line e dados de citação de pesquisas com temáticas étnico-raciais: um comparativo entre publicações sobre afrodescendentes brasileiros e americanos. In: ENCONTRO BRASILEIRO DE BIBLIOMETRIA E CIENTOMETRIA, 7., 2020, Salvador. Anais [...] Salvador: UFBA, 2020. p. 205-211. Disponível em: https://repositorio.ufba.br/ri/handle/ri/32385. Acesso em: 30 nov. 2020.

SILVA, F. C. G (org.). Mulheres negras na Biblioteconomia. Florianópolis: Rocha Gráfica e Editora, Selo Nyota, 2019.

SILVA, F. C. G.; LIMA, G. S. (org.) Bibliotecári@ s negr@s: ação, pesquisa e atuação política. Florianópolis: Associação Catarinense de Bibliotecários, 2018.

SUD, P.; THELWALL, M. Evaluating altmetrics. Scientometrics, v. 98, n. 2, p. 1131-1143, 2014. Disponível em: https://doi-org.ez27.periodicos.capes.gov.br/10.1007/s11192-0131117-2. Acesso em: 21 set. 2021.

THELWALL, M. Dimensions: A competitor to Scopus and the Web of Science? Journal of Informetrics, v. 12, n. 2, p. 430-435, mar. 2018. Disponível em:

https://doi.org/10.1016/j.joi.2018.03.006. Acesso em: 30 nov. 2020. 
THELWALL, M. et al. Do Altmetrics Work? Twitter and Ten Other Social Web Services. PLoS ONE, v. 8, n. 5, p. 1-7, 2013. Disponível em:

https://journals.plos.org/plosone/article?id=10.1371/journal.pone.0064841. Acesso em: 30 nov. 2020.

VALÉRIO, E. D.; BERNARDINO, M. C. R.; SILVA, J. A produção científica sobre os (as) negros nos ENANCIBs sob um olhar cientométrico. Informação \& Sociedade: Estudos, João Pessoa, v. 22, n. 2, ago. 2012. Disponível em:

https://periodicos.ufpb.br/ojs2/index.php/ies/article/view/12247. Acesso em: 03 nov. 2020.

VELEZ, L; VILLA-NICHOLAS, M. Mapping race and racism in US library history literature, 1997-2015. Library Trends, v. 65, n. 4, p. 540-554, 2017. Disponível em:

https://doi.org/10.1353/lib.2017.0017. Acesso em: 21 set. 2021.

\section{NOTAS}

\section{CONTRIBUIÇÃO DE AUTORIA}

Concepção e elaboração do manuscrito: S. R. O. Santos, R. F. Araújo

Coleta de dados: S. R. O. Santos

Análise de dados: S. R. O. Santos, R. F. Araújo

Discussão dos resultados: S. R. O. Santos, R. F. Araújo

Revisão e aprovação: R. F. Araújo

\section{CONJUNTO DE DADOS DE PESQUISA}

Todo o conjunto de dados que dá suporte aos resultados deste estudo foi publicado no próprio artigo.

\section{FINANCIAMENTO}

O presente trabalho foi realizado com apoio da Coordenação de Aperfeiçoamento de Pessoal de Nível Superior - Brasil (CAPES) - Código de Financiamento 001.

\section{LICENÇA DE USO}

Os autores cedem à Encontros Bibli os direitos exclusivos de primeira publicação, com o trabalho simultaneamente licenciado sob a Licença Creative Commons Attribution (CC BY) 4.0 International. Estra licença permite que terceiros remixem, adaptem e criem a partir do trabalho publicado, atribuindo o devido crédito de autoria e publicação inicial neste periódico. Os autores têm autorização para assumir contratos adicionais separadamente, para distribuição não exclusiva da versão do trabalho publicada neste periódico (ex.: publicar em repositório institucional, em site pessoal, publicar uma tradução, ou como capítulo de livro), com reconhecimento de autoria e publicação inicial neste periódico.

\section{PUBLISHER}

Universidade Federal de Santa Catarina. Programa de Pós-graduação em Ciência da Informação. Publicação no Portal de Periódicos UFSC. As ideias expressadas neste artigo são de responsabilidade de seus autores, não representando, necessariamente, a opinião dos editores ou da universidade.

\section{EDITORES}

Enrique Muriel-Torrado, Raymundo N. Machado, Valdineia Barreto Ferreira, Kátia de Oliveira Rodrigues, Susane Barros e Genilson Geraldo.

\section{HISTÓRICO}

Recebido em: 15-12-2020 - Aprovado em: 30-08-2021 - Publicado em: 15-10-2021. 